\title{
A RETROSPECTIVE STUDY OF PATIENT COMPLIANCE TO NARROW BAND ULTRAVIOLET B PHOTOTHERAPY IN VITILIGO PATIENTS
}

\author{
Nayeem Sadath Haneef', Bomma Yadagiri Praveen Kumar², Nikhat ${ }^{3}$
}

1 Professor and HOD, Department of Dermatology, Venereology and Leprosy, Deccan College of Medical Sciences, Hyderabad. ${ }^{2}$ Assistant Professor, Department of Dermatology, Venereology and Leprosy, Deccan College of Medical Sciences, Hyderabad. ${ }^{3}$ Assistant Professor, Department of Dermatology, Venereology and Leprosy, Deccan College of Medical Sciences, Hyderabad.

\section{ABSTRACT}

\section{BACKGROUND}

Narrow band ultraviolet B (NBUVB) phototherapy is a well-established, effective and relatively safe treatment modality for treatment of vitiligo. An essential prerequisite for efficacy of NBUVB phototherapy is good compliance by patients. There is a paucity of literature on patient compliance to requisite number of sessions of NBUVB therapy in patients of vitiligo, where phototherapy is required for a prolonged duration.

\section{MATERIALS AND METHODS}

A 2-year retrospective analytical study was conducted to analyse patient compliance to NBUVB phototherapy in patients of vitiligo. All the patients were advised to visit the hospital for phototherapy thrice a week. Thus, in the initial 3 months (13 weeks), prescribed number of phototherapy sessions amounts to 39. Based on the actual number of phototherapy sessions completed by patients during this initial 3 months period, patient compliance to NBUVB therapy was graded as excellent (completion of $>75 \%$ of prescribed number of sessions), good (completion of $>50-75 \%$ of prescribed number of sessions), poor (completion of $>25-50$ $\%$ of prescribed number of sessions) and very poor (completion of $<25 \%$ of prescribed number of sessions).

\section{RESULTS}

During the 2-year study period, 33 patients of vitiligo were prescribed narrow band UVB phototherapy, of which 11 patients dropped out after less than 8 sessions of phototherapy. Of the remaining 22 patients, only 5 patients $(22.72 \%)$ had excellent compliance (completed $>75 \%$ of prescribed number of sessions), 3 patients $(13.63 \%)$ had good compliance $(>50-75 \%$ of prescribed number of sessions), 12 patients (54.54\%) had poor compliance ( $>25-50 \%$ of prescribed number of sessions) and 2 patients $(9.09 \%)$ had very poor compliance $(<25 \%$ of prescribed number of sessions). Most common reasons for poor compliance were difficulty in adjusting school/college timings (42.85\%) and distance/transport problems (35.71\%).

\section{CONCLUSION}

Poor patient compliance to narrow band UVB phototherapy, as observed in majority of patients in the present study, may be due to several reasons. Poor compliance may adversely impact the efficacy of this excellent therapeutic modality in patients of vitiligo.

\section{KEYWORDS}

Phototherapy, Vitiligo, Compliance, Narrow Band Ultraviolet B Therapy.

HOW TO CITE THIS ARTICLE: Haneef NS, Kumar BYP, Nikhat. A retrospective study of patient compliance to narrow band ultraviolet B phototherapy in vitiligo patients. J. Evolution Med. Dent. Sci. 2017;6(21):1662-1666, D0I: 10.14260/Jemds/2017/366

\section{BACKGROUND}

Vitiligo is the most common depigmentary disorder, having significant impact on quality of life. ${ }^{1}$ It is seen in about $1 \%$ population of the world, but it is much commoner in India, the incidence being 3-9\% according to various Indian studies. ${ }^{2}$ Though exact pathomechanism is unknown, it is thought to occur as a result of melanocyte damage due to various mechanisms, including autoimmune, cytotoxic, free radicals, neural and melanocytic self-destructive mechanisms. ${ }^{1}$ Clinically, this melanocyte damage manifests as asymptomatic, well-defined, depigmented or hypopigmented

Financial or Other, Competing Interest: None.

Submission 31-01-2017, Peer Review 12-02-2017,

Acceptance 15-02-2017, Published 13-03-2017.

Corresponding Author:

Dr. Nayeem Sadath Haneef,

3/102, Kalyani, Sahara States,

Mansoorabad, LB Nagar,

Hyderabad - 50008,

India.

E-mail: dr_nayeemsadath@yahoo.co.in

DOI: $10.14260 /$ jemds $/ 2017 / 366$

\section{(c) $(1) \ominus$}

macules, which may be localised to few sites or even generalised. ${ }^{3}$ There are various medical treatments such as topical or oral corticosteroids, topical tacrolimus, pimecrolimus, etc. as well as surgical treatments like minipunch grafting, melanocyte transfers, etc. ${ }^{3}$ Phototherapy, including psoralen ultraviolet A (PUVA) and narrow band ultraviolet B (NBUVB) are well-established, effective treatment modalities for vitiligo, especially when it is extensive. ${ }^{4}$ Narrow band ultraviolet B (NBUVB) phototherapy with a sharp emission peak at 311 to $313 \mathrm{~nm}$ is safer than PUVA and almost equally effective, especially for treatment of childhood vitiligo.3,5 An essential prerequisite for efficacy of NBUVB phototherapy is good compliance by patients. There is a paucity of literature on patient compliance to requisite number of sessions of NBUVB therapy in patients of vitiligo, where phototherapy is required for a prolonged duration. ${ }^{6}$

\section{MATERIALS AND METHODS}

Objective

To analyse patient compliance to narrow band ultraviolet $\mathrm{B}$ (NBUVB) phototherapy in patients of vitiligo, and to evaluate factors affecting the compliance. 


\section{Study Design}

Retrospective data based analytical study.

\section{Setting}

Dermatology, Venereology and Leprosy Department of a Tertiary Care Hospital attached to a postgraduate training institute in Telangana State of India.

\section{Period}

Two years (from January 2015 to December 2016).

\section{Inclusion Criteria}

Patients of vitiligo, diagnosed clinically or histopathologically, who had been advised NBUVB phototherapy.

\section{Exclusion Criteria}

Patients who dropped out and who were lost for follow up after less than 8 sessions of phototherapy were excluded from the evaluation, since cause for noncompliance to phototherapy could not be ascertained.

\section{Treatment/Evaluation Protocol}

The patients of vitiligo who were advised narrow band UVB phototherapy were treated with gradually increasing dose of NBUVB in either whole body phototherapy unit or hand and foot phototherapy unit depending on the distribution of vitiligo lesions. Both instruments had Philips TL 01 ultraviolet lamps, emitting ultraviolet light in the narrow band peak of 311-313 nm wavelength. The patients were asked to undergo this therapy thrice a week. ${ }^{5}$ Thus, in the initial 3 months (13 weeks), prescribed number of phototherapy sessions amounts to 39. Data pertaining to actual number of phototherapy sessions by the patients was analysed. Based on the actual number of phototherapy sessions completed by the patients during this initial 3 months period, patient compliance to NBUVB therapy was graded as excellent (completion of $>75 \%$ of prescribed number of sessions), good (completion of $>50-75 \%$ of prescribed number of sessions), poor (completion of $>25$ $50 \%$ of prescribed number of sessions) and very poor (completion of $<25 \%$ of prescribed number of sessions). Factors and difficulties quoted by patients affecting their compliance to phototherapy were tabulated and analysed.

\section{RESULTS}

As per the data pertaining to the 2-year study period, 33 patients of vitiligo were prescribed narrow band UVB phototherapy, of which 11 patients dropped out within less than 8 sessions of phototherapy. Of the remaining 22 patients, age of the patients ranged from 7 to 65 years. Most patients, i.e. 6 patients $(27.27 \%)$ belonged to $31-40$ years age group followed by 4 patients $(18.18 \%)$ in 41 - 50 years age group (Table 1; Figure 1). There were 11 male (50\%) and 11 female (50\%) patients (Table 2; Figure 2). Most patients were housewives ( 9 patients; $40.90 \%$ ) followed by 6 patients $(27.27 \%)$ who were either school or college students (Table 3; Figure 3). Among the 22 patients in whom the compliance to phototherapy (ideally, 3 sessions per week $\times 13$ weeks $=$ 39 sessions in 3 months) was graded, highest compliance of 31 sessions $(89.74 \%)$ was seen in a 58-year-old doctor. Only 5 patients $(22.72 \%)$ had excellent compliance (completed > $75 \%$ of prescribed number of sessions), 3 patients $(13.63 \%)$ had good compliance $(>50-75 \%$ of prescribed number of sessions), 12 patients (54.54\%) had poor compliance ( $>25$ $50 \%$ of prescribed number of sessions) and 2 patients (9.09\%) had very poor compliance, defined as $<25 \%$ of prescribed number of sessions (Table 4; Figure 4). Most common reasons for poor compliance were difficulty in adjusting school/college timings in 6 patients $(42.85 \%$ among those with poor/very poor compliance) and distance/transport problems in 5 patients $(35.71 \%$ among those with poor/very poor compliance). Difficulty in adjusting office/business timings was quoted by 2 patients (14.28\% among those with poor/very poor compliance) and financial problem leading to non-affordability of phototherapy by 1 patient $(7.14 \%$ among those with poor/very poor compliance). Phototherapy was well tolerated in all the 22 patients studied.

\begin{tabular}{|c|c|c|}
\hline Age Group (years) & No. of Patients & Percentage \\
\hline $1-10$ years & 3 & $13.63 \%$ \\
\hline $11-20$ years & 3 & $13.63 \%$ \\
\hline $21-30$ years & 3 & $13.63 \%$ \\
\hline $31-40$ years & 6 & $27.27 \%$ \\
\hline $41-50$ years & 4 & $18.18 \%$ \\
\hline $51-60$ years & 1 & $4.54 \%$ \\
\hline $61-70$ years & 2 & $9.09 \%$ \\
\hline \multicolumn{2}{|c|}{ Table 1. Age Distribution (n=22) } \\
\hline
\end{tabular}

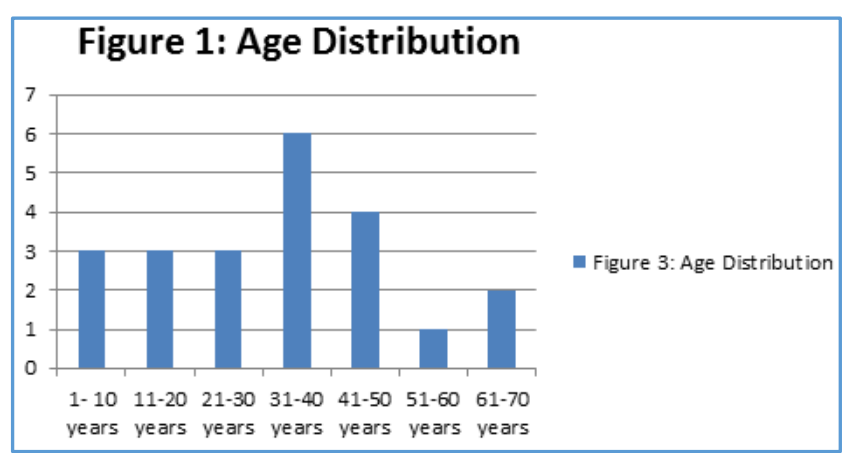

\begin{tabular}{|c|c|c|}
\hline Sex & No. of Patients & Percentage \\
\hline Male & 11 & $50 \%$ \\
\hline Female & 11 & $50 \%$ \\
\hline \multicolumn{3}{|c|}{ Table 2. Sex Distribution (n=22) } \\
\hline
\end{tabular}

\section{Figure 2: Sex Distribution}

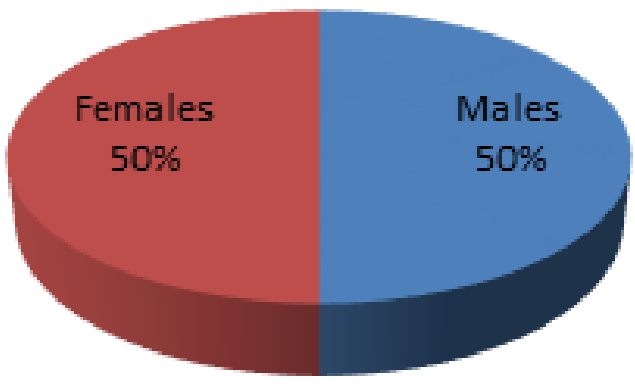




\begin{tabular}{|c|c|c|}
\hline $\begin{array}{c}\text { Occupation of } \\
\text { Patients }\end{array}$ & $\begin{array}{c}\text { No. of } \\
\text { Patients }\end{array}$ & $\begin{array}{c}\text { Percentage of } \\
\text { Patients }\end{array}$ \\
\hline Housewife & 9 & $40.90 \%$ \\
\hline $\begin{array}{c}\text { School/college } \\
\text { students }\end{array}$ & 6 & $27.27 \%$ \\
\hline Business & 4 & $18.18 \%$ \\
\hline Doctor & 1 & $4.54 \%$ \\
\hline Retired office employee & 1 & $4.54 \%$ \\
\hline Office employee & 1 & $4.54 \%$ \\
\hline \multicolumn{2}{|c|}{ Table 3. Occupation of Patients (n=22) } \\
\hline
\end{tabular}
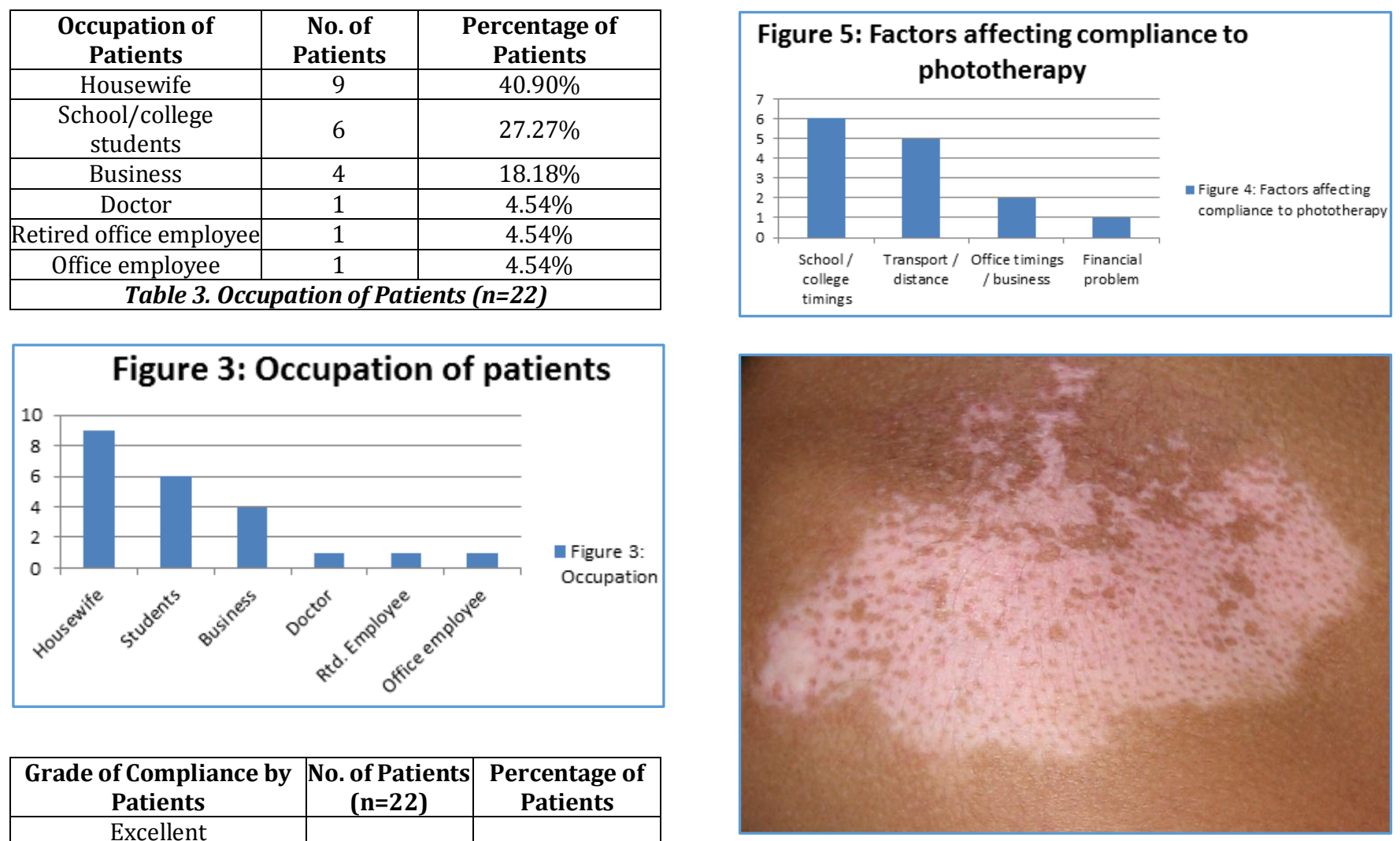

\begin{tabular}{|c|c|c|}
\hline $\begin{array}{c}\text { Grade of Compliance by } \\
\text { Patients }\end{array}$ & $\begin{array}{c}\text { No. of Patients } \\
\text { (n=22) }\end{array}$ & $\begin{array}{c}\text { Percentage of } \\
\text { Patients }\end{array}$ \\
\hline $\begin{array}{c}\text { Excellent } \\
\text { (> 75\% of prescribed } \\
\text { number of sessions) }\end{array}$ & 5 & $22.72 \%$ \\
\hline $\begin{array}{c}\text { Good } \\
\text { (>50-75\% of prescribed } \\
\text { number of sessions) }\end{array}$ & 3 & $13.63 \%$ \\
\hline $\begin{array}{c}\text { Poor } \\
\text { (>25-50\% of prescribed } \\
\text { number of sessions) }\end{array}$ & 12 & $54.54 \%$ \\
\hline $\begin{array}{c}\text { Very Poor } \\
\text { (<25\% of prescribed } \\
\text { number of sessions) }\end{array}$ & 2 & $9.09 \%$ \\
\hline \multicolumn{2}{|c|}{ Table 4. Patient Compliance to Phototherapy } \\
\hline
\end{tabular}

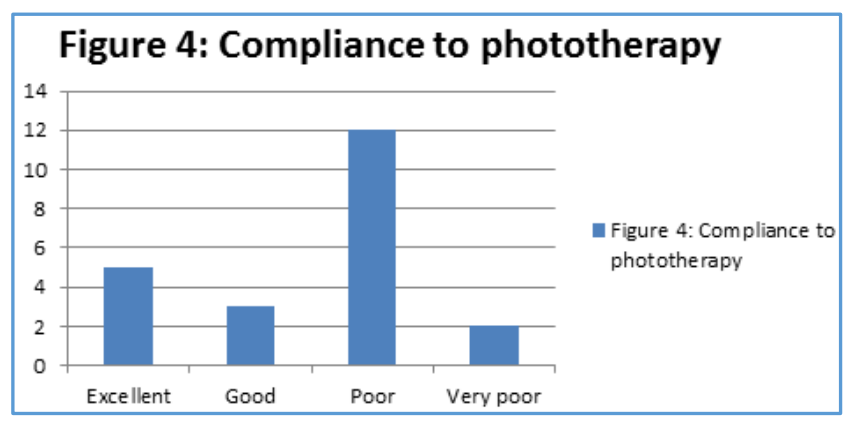

\begin{tabular}{|c|c|c|}
\hline $\begin{array}{c}\text { Causes for } \\
\text { Poor/Very Poor } \\
\text { Compliance by } \\
\text { Patients }\end{array}$ & $\begin{array}{c}\text { No. of Patients (n=14) } \\
\text { (Excluding those with } \\
\text { Excellent/Good } \\
\text { Compliance) }\end{array}$ & $\begin{array}{c}\text { Percentage of } \\
\text { Patients }\end{array}$ \\
\hline $\begin{array}{c}\text { School/college } \\
\text { timings }\end{array}$ & 6 & $42.85 \%$ \\
\hline Transport/distance & 5 & $35.71 \%$ \\
\hline $\begin{array}{c}\text { Office } \\
\text { timings/business }\end{array}$ & 2 & $14.28 \%$ \\
\hline Financial problem & 1 & $7.14 \%$ \\
\hline Table 5. Factors Affecting Compliance to Phototherapy \\
\hline
\end{tabular}

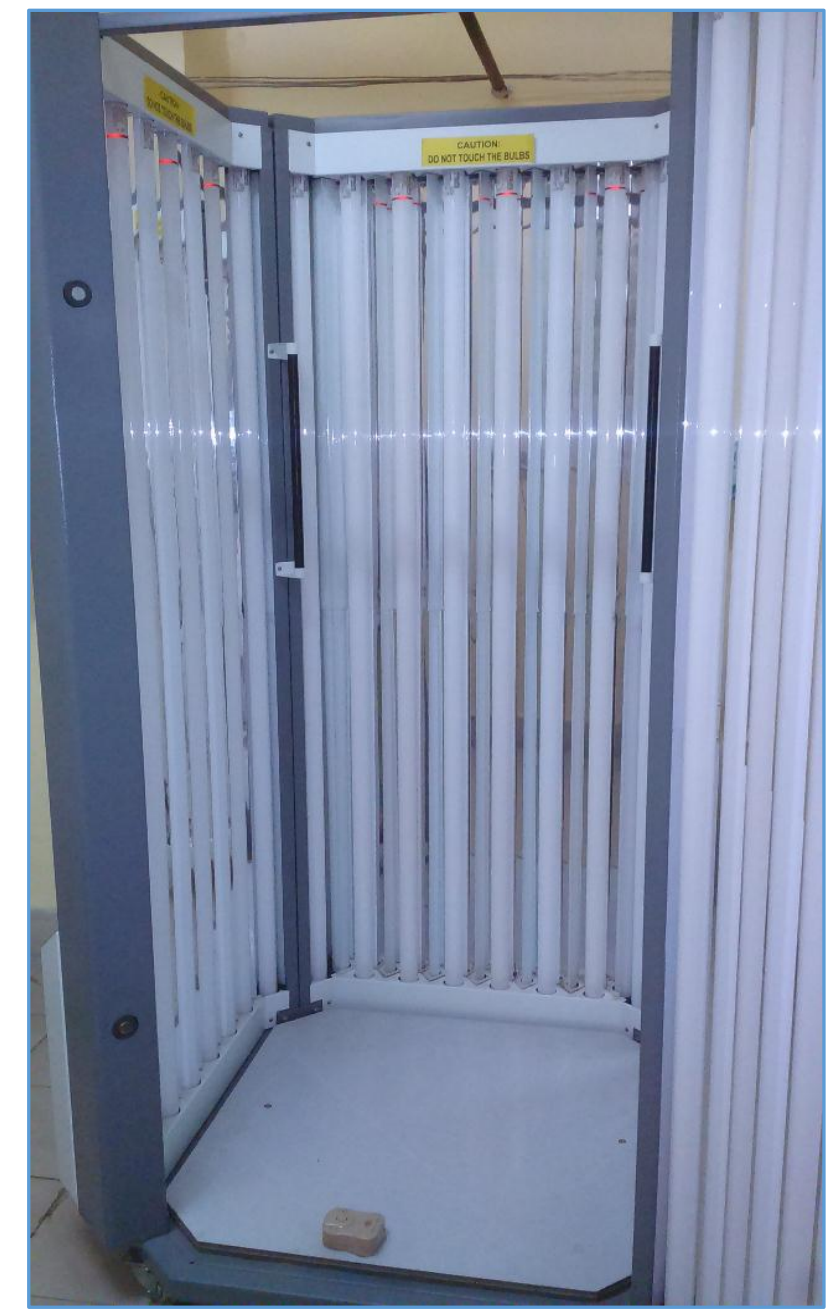

Figure 7. Whole Body Phototherapy Chamber 


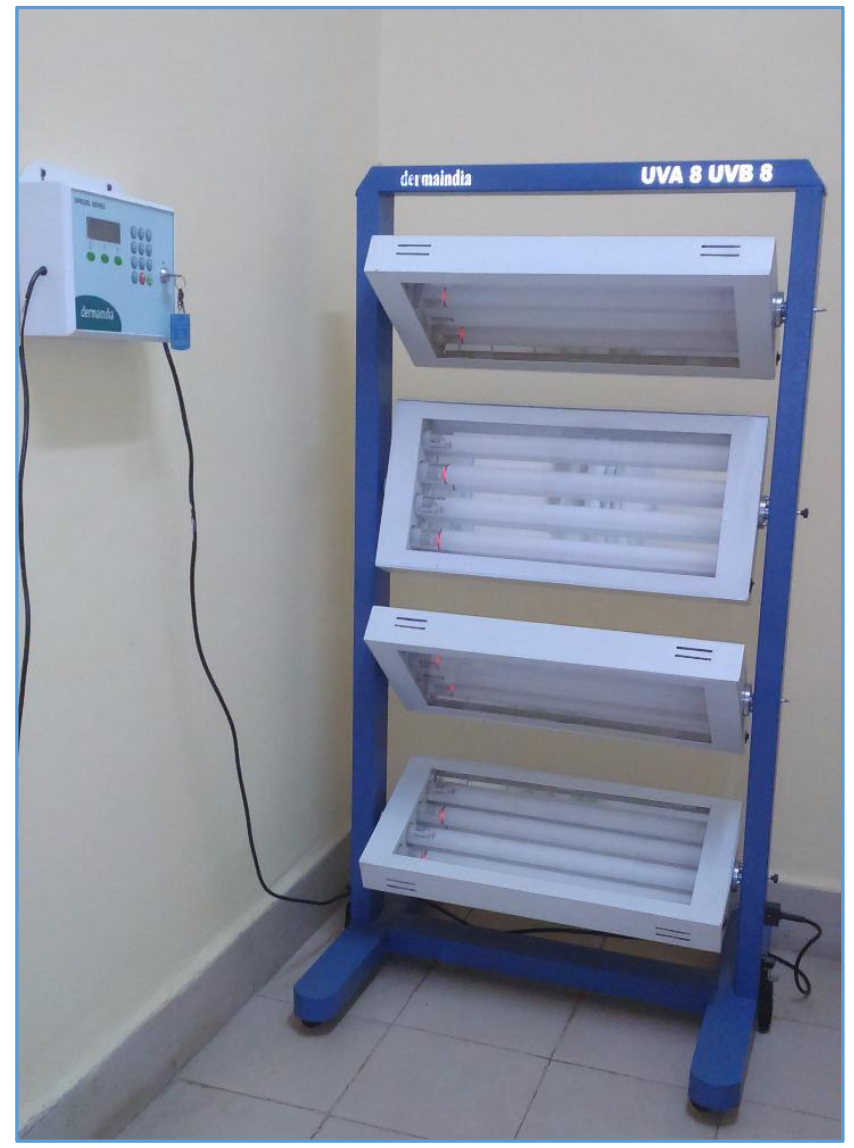

Figure 8. Hand and Foot Phototherapy Equipment

\section{DISCUSSION}

Vitiligo is a cosmetically disfiguring disease, especially in darker skin races such as Indians (Figure 6). ${ }^{7}$ Apart from topical and systemic corticosteroids which are commonly used for the treatment of this disease, many new topical treatment modalities are emerging such as tacrolimus, pimecrolimus, basic fibroblast growth factor, etc. ${ }^{7}$ Novel systemic therapies like L-phenylalanine, Polypodium leucotomos, Khellin, Ginkgo biloba, vitamins B12, C, E, folic acid and zinc have also been found to be effective. ${ }^{8}$ However, phototherapy is the most commonly used treatment modality in extensive vitiligo.9,10 Phototherapy equipment of various types, including whole body type (Figure 7) or hand and foot type (Figure 8) can be used, in addition to innovative equipment to suit different type of needs such as handheld, home based equipment. These phototherapy equipment can emit UVA, narrow band UVB or both. Narrow-band ultraviolet B (NBUVB) therapy is preferred over PUVA as the latter is associated with many short- and long-term side-effects. ${ }^{11,12}$ NBUVB is especially valuable in childhood vitiligo, as almost half the patients of vitiligo have onset before 20 years, and NBUVB is much safer in this age group as compared to PUVA. 2,3 The present study was conducted to evaluate the pattern of patient compliance to narrow band ultraviolet $B$ (NBUVB) phototherapy in patients of vitiligo, and to evaluate the factors affecting the compliance, since there is a paucity of literature on this aspect despite there being numerous studies comparing efficacy and safety of NBUVB with that of PUVA or other treatment modalities in vitiligo. ${ }^{11,12}$ In the present study, it was found that 11 out of 33 patients put on NBUVB phototherapy dropped out within 8 sessions. Exact reason for these early dropouts could not be ascertained. Of the remaining 22 patients, only 8 patients had taken more than $50 \%$ of the prescribed number of phototherapy sessions. Remaining 14 patients who received less than $50 \%$ of the requisite number of sessions, most common reasons quoted for noncompliance were difficulty in adjusting with school, college, office or business timings and difficulty in transport due to distance. Kandaswamy et al studied compliance to phototherapy (both PUVA and NBUVB) in 79 patients of vitiligo and found that only 21 patients were regular and 58 patients were irregular or noncompliant. ${ }^{6}$ They found that the most common factor (22.8\% patients) for noncompliance was development of adverse effects such as erythema, itching, burning sensation, pigmentation, blistering, oedema, eye pain and visual problems. ${ }^{6}$ However, none of the 22 patients in our present study complained of them, since all the patients studied received only NBUVB, which is not associated with such troublesome adverse effects as seen in PUVA. Second commonest cause for noncompliance in Kandaswamy study was distance to be travelled by the patients, which was also observed in our present study. ${ }^{6}$ Kumar et al found better therapeutic response to NBUVB in those with good compliance, though they were advised only 2 sessions per week in their study. ${ }^{10}$ Poor compliance to narrow band UVB phototherapy, as found in majority of patients in the present study may adversely affect the therapeutic efficacy of this promising new therapy in patients of vitiligo. Hence, more intense counselling by dermatologists as well as better cooperation and lifestyle adjustment by patients may help improve the compliance to phototherapy in patients of vitiligo, thereby improving the therapeutic outcome.

\section{CONCLUSION}

Poor patient compliance to narrow band UVB phototherapy, as observed in majority of patients in the present study, may be due to several reasons. Poor compliance may adversely impact the efficacy of this excellent therapeutic modality in patients of vitiligo.

\section{REFERENCES}

[1] Prasad D. Vitiligo: emerging paradigms. Indian J Dermatol Venereol Leprol 2012;78(1):17-8.

[2] Shah H, Mehta A, Astik B. Clinical and sociodemographic study of vitiligo. Indian J Dermatol Venereol Leprol 2008;74(6):701.

[3] Palit A, Inamadar AC. Childhood vitiligo. Indian J Dermatol Venereol Leprol 2012;78(1):30-41.

[4] El-Mofty M, Mostafa WZ, Bosseila M, et al. A large scale analytical study on efficacy of different photo (chemo) therapeutic modalities in the treatment of psoriasis, vitiligo and mycosis fungoides. Dermatol Ther 2010;23(4):428-34.

[5] Hamzavi IH, Lim HW, Syed ZU. Ultraviolet-based therapy for vitiligo: what's new? Indian J Dermatol Venereol Leprol 2012;78(1):42-8.

[6] Kandaswamy S, Akhtar N, Ravindran S, et al. Phototherapy in vitiligo: assessing the compliance, response and patient's perception about disease and treatment. Indian J Dermatol 2013;58(4):325.

[7] Lotti T, Gori A, Zanieri F, et al. Vitiligo: new and emerging treatments. Dermatol Ther 2008;21(2):110-7. 
[8] Cohen BE, Elbuluk N, Mu EW, et al. Alternative systemic treatments for vitiligo: a review. Am J Clin Dermatol 2015;16(6):463-74.

[9] Kanwar AJ, Dogra S, Parsad D, et al. Narrow-band UVB for the treatment of vitiligo: an emerging effective and well-tolerated therapy. Int J Dermatol 2005;44(1):5760.

[10] Kumar YH, Rao GR, Gopal KV, et al. Evaluation of narrow-band UVB phototherapy in 150 patients with vitiligo. Indian J Dermatol Venereol Leprol 2009;75(2):162-6.
[11] Rath N, Kar HK, Sabhnani S. An open labeled, comparative clinical study on efficacy and tolerability of oral minipulse of steroid (OMP) alone, OMP with PUVA and broad/narrow band UVB phototherapy in progressive vitiligo. Indian J Dermatol Venereol Leprol 2008;74(4):357-60.

[12] Nicolaidou E, Antoniou C, Stratigos AJ, et al. Efficacy, predictors of response, and long-term follow-up in patients with vitiligo treated with narrowband UVB phototherapy. J Am Acad Dermatol 2007;56(2):274-8. 